\title{
THE USAGE OF COMPUTER VISUALIZATION IN TEACHING TECHNICAL SUBJECTS
}

\author{
Krzysztof Dziedzic'ㅜ, Maciej Włodarczyk², Magdalena Paśnikowska ${ }^{3}$
}

1 Faculty of Fundamentals of Technology, Lublin University of Technology, Nadbystrzycka 38, 20-618 Lublin, Poland, e-mail:k.dziedzic@pollub.pl

${ }^{2}$ Mechanical Engineering Faculty, Lublin University of Technology, Nadbystrzycka 36, 20-618 Lublin, Poland, e-mail: m.wlodarczyk@pollub.pl

3 Student of the Faculty of Fundamentals of Technology, Lublin University of Technology, Nadbystrzycka 38, 20-618 Lublin, Poland

Received: 2014.09.25

Accepted: 2014.10 .25

Published: 2014.12.01

\begin{abstract}
Computer 3D modelling allows designing or mapping objects and then their photorealistic visualization. In the programs for creating 3D graphics a user often loses judgement as to which technique to use during the process. It is also a major problem in teaching graphics, because the final result can be obtained by various methods using tools available in the programs. This paper presents and discusses the examples of the usage of computer visualization in teaching technical subjects on science faculties. For this purpose CAD programs, such as Inventor and AutoCAD were used. The advantages of 3D over 2D design were described and the analysis and evaluation of the available tools for 3D modelling and computer visualization were conducted. In the final part of the work selected examples of computer visualization are presented, in the context of supporting teaching the students of science fields of studies.
\end{abstract}

Keywords: computer visualization, computer modeling, teaching.

\section{INTRODUCTION}

The teaching of technical subjects, such as engineering, graphics or machine design basics of technical fields, until recently, was taught through the use of traditional methods of calculation and drawing. Nowadays, the development of computers and software allows you to use them to support the work of the modern engineer. Initially, it was to complete the traditional techniques by replacing a drawing board and calculator. But now, the use of computers with specialized software, replaces almost entirely the traditional methods. Computer programs are used, inter alia, on the stages of product design, engineering calculations and manufacturing of devices. Increasingly, during these processes the computer visualization is used. Computer visualization is the common name for graphical methods to create, analyse and communicate information. It is most commonly used in typical industrial sectors, such as the construction industry, machine, energy, etc,. but also in medicine, advertising, photography and many other areas of life. Visualization also affects the methods conducting research, and also serves educational purposes [1]. In the process of teaching, the use of 3D modelling and computer visualization creates new opportunities for knowledge transfer. It makes technical issues presented on typically technical subjects, easier to understand interpret and prepare the documentation. As an example, during engineering manufacturing classes, a student can design a product, using modelling and visualization, create a computer model, prepare its documentation, and then produce it. It is also worth noting that by performing work with programs that use computer visualization and $3 \mathrm{D}$ modelling, people develop its technical and spatial imagination, which is of great importance in the preparatory process of the product. 


\section{PROGRAMS CAD / CAM / CAE}

Nowadays, there are many programs for 3D modelling and computer visualization on the market. Various application programs can be distinguished here, such as 3 ds Max, Blender or Maya 3D. In engineering applications, as well as science education programs from the group of CAD / CAM / CAE are predominantly used. They are among the programs which are part of CIM (Computer Integrated Manufacturing). They are used most often to aid engineering in the design and manufacture of a product. Under the term CAD / CAM / CAE we understand Computer Aided Design, Computer Aided Manufacturing and Computer Aided Engineering. These are the main tools used by modern engineers, regardless of their industry. Therefore, it is an essential element of the education of future engineers, studying technical fields.

Computer Aided Design (CAD) involves the use of programs and computer equipment during engineering design. Characteristic of CAD is creating digital geometric models that determine the structural form of the product (one or more objects). Computer-aided design software is meant to support the work of the engineer mostly in the early stages of product development. CAD programs are not only applicable when creating and modifying 2D construction documentation, but especially in 3D modelling, performing assembly, presentation and analysis of endurance where computer visualization is applicable (Figure 1abc). CAD software can be used for documentation of the treatment process used in the conventional machines, and for the preparation of 2D/3D models used in CAM programs.

Computer-aided manufacturing (CAM) is the integration of the design and manufacturing phases. CAM software facilitates designing technological processes. A characteristic feature of computer software, which facilitates the preparation processing of the models which arise in computer modelling 2D/3D into machine control instructions in CNC machine tools, which allow processing the elements [2]. Computer visualization is used here, for example in verifying whether there are no collisions of a tool with the workpiece or any part of the machine, during the machining etc.

Computer Aided Engineering (CAE) is the use of computer programs to simulate the functioning of the product. This is to improve proj- ects and support processes of resolving design errors [4].

The Examples of CAD programs are Auto$\mathrm{CAD}$ and Inventor. AutoCAD is a commercial program created and distributed by Autodesk. It is used for computer-aided design in 2D and 3D. Originally, it was used mainly by technicians. Currently it is used by architects, electricians and other designers due to the fact that Autodesk has expanded the program with many specialized overlays such as AutoCAD Electrical, AutoCAD Mechanical, Mechanical Desktop, Architectural Desktop, Civil Design, etc. Since 2005 version, the program has become a good tool for creating 3D models, with which you can create photorealistic visualizations. With AutoCAD, the most commonly created is $2 \mathrm{D}$ documentation, and then, based on it, 3D models and their visualization are made [4-6].

Autodesk Inventor is another commercial Autodesk program. It is a parametric system which allows designing objects in 3D space, with a possibility to create $2 \mathrm{D}$ and $3 \mathrm{D}$ documentation. During the labour hierarchical models are created as sequential trees of a history of operations performed by the user. Inventor also enables the creation of assemblies based on 3D models and performing their presentation [7-9]. Autodesk Inventor HSM Express 2014 is a free CAM solution for computer-aided manufacturing, which is integrated with Autodesk Inventor design environment. It Includes strategies of generating tool paths for milling, drilling, dredging and drilling. After generating tool paths, the results of simulation can be checked using the player (Figure 1d).

In conclusion, we can say that CAD / CAM / CAE are good tools supporting the work of modern engineers, as well as facilitating the conduct of the process of teaching technical subjects.

\section{AN EXAMPLE OF THE USE OF COMPUTER VISUALIZATION IN INVENTOR IN SCIENCE EDUCATION}

In programs CAD / CAM / CAE user often loses recognition, which of the techniques to use during the work. It is also a major problem in the teaching process, because the final result can be obtained by various methods. Choosing the right tools and modelling techniques is often debatable. In today's computer programs we have a lot of computer techniques used for 
a)

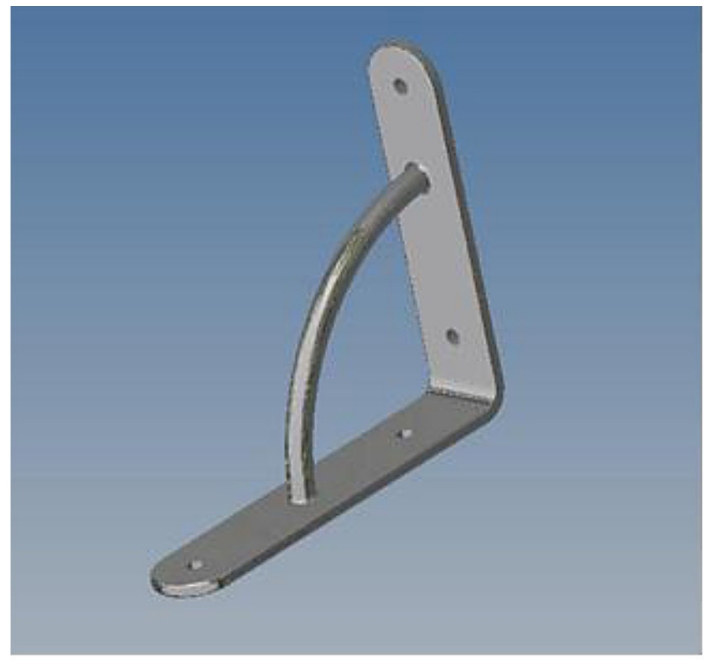

c)

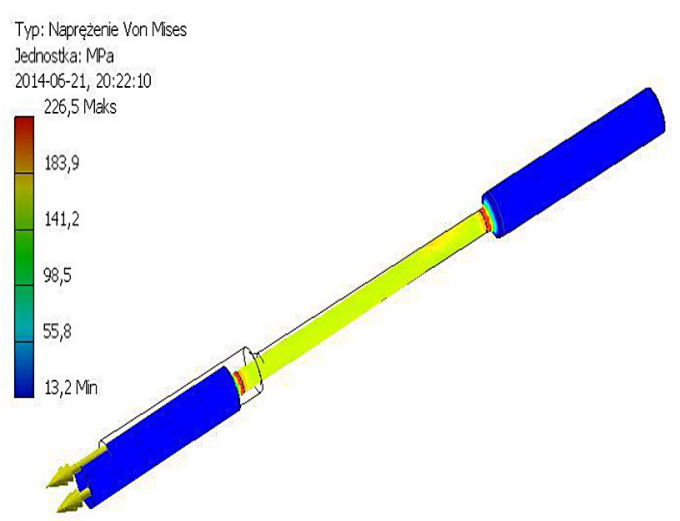

b)

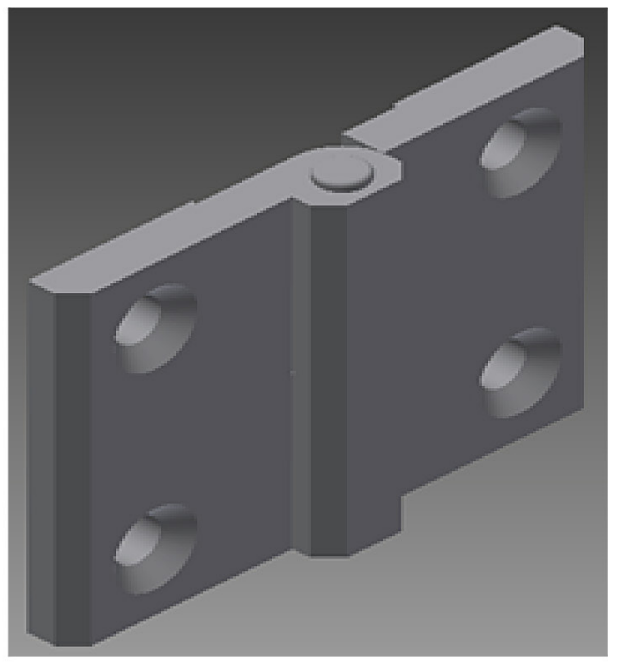

d)

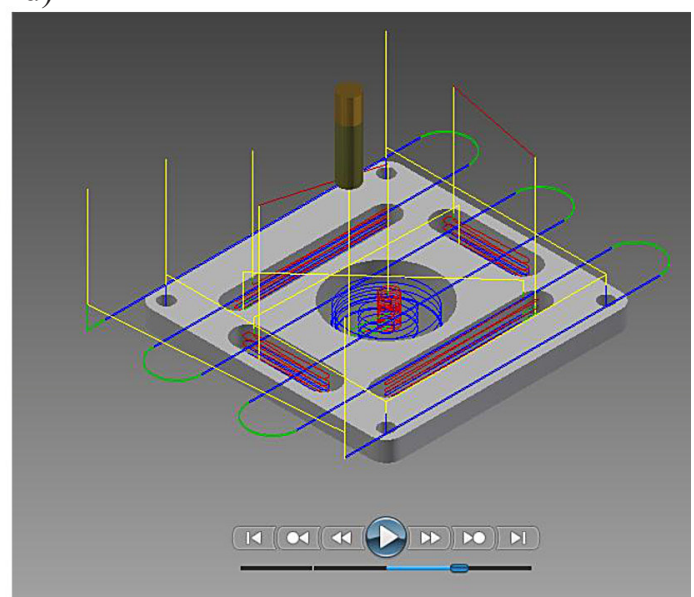

Fig. 1. The use of visualization in Inventor: a) 3D model, b) submission, c) strength analysis, d) tooling of CAM

modelling and visualization of 3D objects. Modelling of three-dimensional parts usually starts with a two-dimensional 2D sketch that defines their shape. A good example include the tools for sketching in Inventor. When you create a sketch in Inventor, information about relations is registered additionally. Due to relations (bonding), the process of editing the sketch is easier, as long as they are properly applied. The Sketch is launched on the sketch plane, on which episodes, arcs, circles, etc. are plotted. The generated sketch becomes a profile which is used as the basis for the operation of creation of a 3D object The basic techniques to create 3D objects in Inventor; among others are: Extrude, Rotate, Loft and Drag. Necessary for the modelling of very complex objects are auxiliary construction elements, such as: surface, axis, or point coordinate system. The Planes are primarily used as a space for sketching when there is no plane of a part suitable for creating two-dimensional sketches of elements. On the basis of the 3D model it is possible to perform 2D documentation. Figure 2 shows a visualization of the 3D model and 2D documentation made on its basis. This is an example, implemented in the classroom, by the students in the field of computer engineering graphics.

\section{CONCLUSION}

Computer Visualization is currently a quickly developing field of applied computer science which can be implemented by using many different programs. In engineering applications as well, these issues have been recognized and continually developed. Programs from the group of CAD / CAM / CAE are examples, which are the basic tool for modern engineers. The use of computer visualization in the teaching of science allows to prepare students more efficiently to carry out 
a)

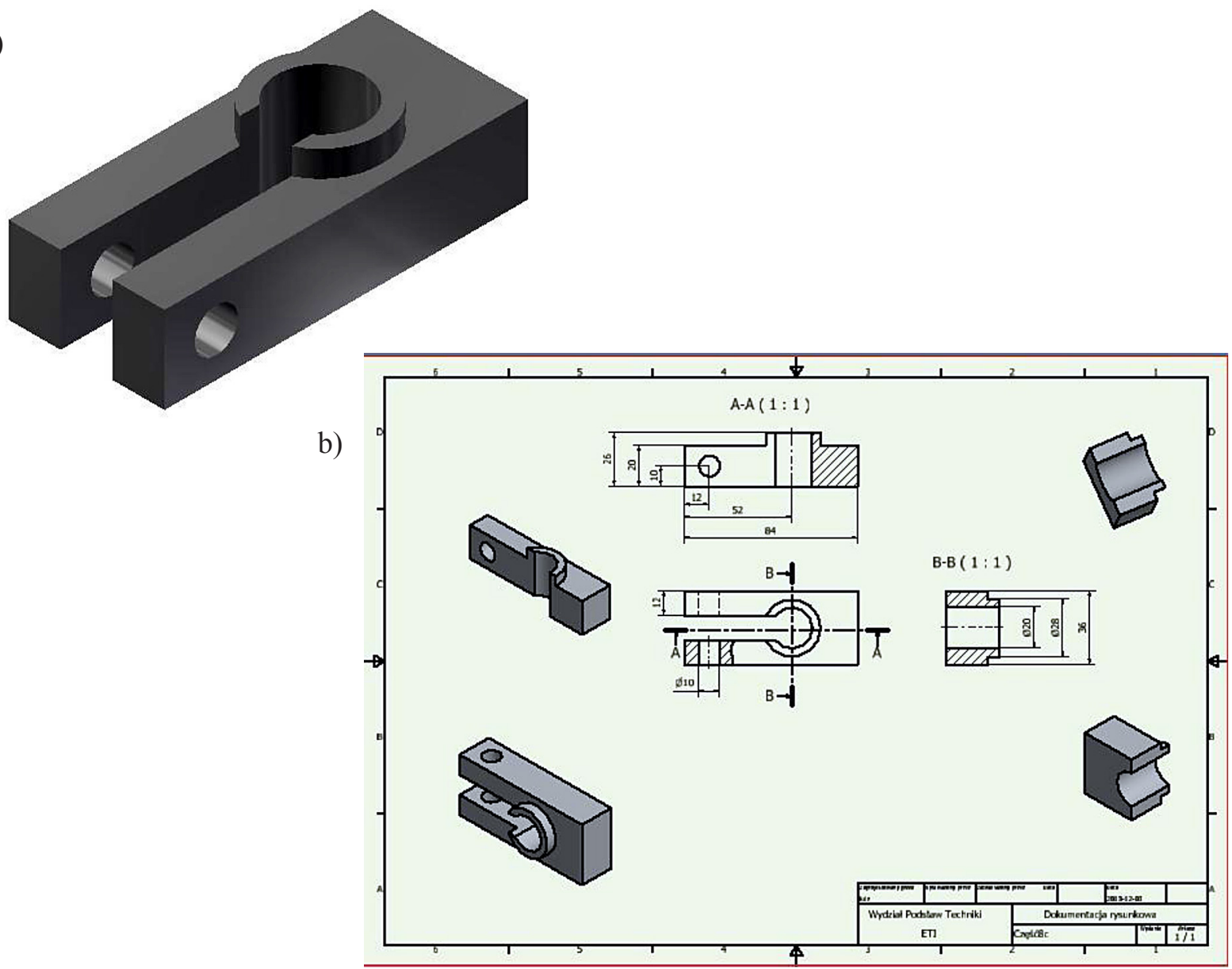

Fig. 2. Modelling in Inventor: a) visualization of the 3D model, b) 2D documentation

tasks which modern engineers face. Projects and theses prepared by the students attest to the fact that many of them have mastered various techniques of modelling and computer visualization during the classes. As a conclusion, one can say that 3D modelling and computer visualization are important tools for teaching students in the technical fields.

\section{REFERENCES}

1. Montusiewicz J, Dziedzic K.: Teaching three-dimensional animation in the direction of the ETI, Postępy Nauki i Techniki, No. 11, 2011, 148-155.

2. Honczarenko J.: Numerically controlled machine tools. Wydawnictwo Nukowe WNT, Warsaw 2008.

3. Park H., Phuong X.: Structural optimization based on CAD-CAE integration and metamodeling tech- niques. Computer-Aided Design, Vol. 42, 2010 , 889-902.

4. Liu Y., Ritchie J.M., Lim T., Kosmadoudi Z., Sivanathan A., Sung R.C.W.: A fuzzy psycho-physiological approach to enable the understanding of an engineer's affect status during CAD activities. Computer-Aided Design, Vol. 54, 2014, 19-38.

5. Jaskulski A.: AutoCAD 2013/LT2013/WS + training parametric design and parametric $2 \mathrm{D}$ and $3 \mathrm{D}$. McGraw-Hill, 2013.

6. Montusiewicz J.: Modeling 2D AutoCAD. Lublin University of Technology, Lublin 2011.

7. Jaskulski A.: Autodesk Inventor Professional. Fusion 2013pl/2013 + design methodology. PWN, Warsaw 2012.

8. Płuciennik P.: Design of machine elements using Autodesk Inventor. PWN, Warsaw 2013.

9. Leg B.: Inventor, Design Basics. Helion, Gliwice 2011. 